\title{
In Vitro Mean Red Blood Cell Volume Change Induced by Diode Pump Solid State Low-Level Laser of $405 \mathrm{~nm}$
}

\author{
Mustafa S. Al Musawi, MSc, ${ }^{1,2}$ Mohamad Suhaimi Jafar, PhD, Bassam T. Al-Gailani, PhD, \\ Naser Mahmoud Ahmed, PhD, Fatanah Mohamad Suhaimi, $\mathrm{PhD}^{3}$, and Nursakinah Suardi, $\mathrm{PhD}^{1}$
}

\begin{abstract}
Objective: This study was conducted to investigate the effects of low-level laser (LLL) doses on human red blood cell volume. The effects of exposure to a diode pump solid state (DPSS) $(\lambda=405 \mathrm{~nm})$ laser were observed. Background data: The response of human blood to LLL irradiation gives important information about the mechanism of interaction of laser light with living organisms. Materials and methods Blood samples were collected into ethylenediaminetetraacetic acid (EDTA)-containing tubes, and each sample was divided into two equal aliquots, one to serve as control and the other for irradiation. The aliquot was subjected to laser irradiation for $20,30,40$, or $50 \mathrm{~min}$ at a fixed power density of $0.03 \mathrm{~W} / \mathrm{cm}^{2}$. Mean cell volume (MCV) and red blood cell (RBC) counts were measured immediately after irradiation using a computerized hemtoanalyzer. Results: Significant decrease in $\mathrm{RBC}$ volume $(p<0.05, p<0.0001, p<0.0001$, and $p<0.05$, respectively) was induced with variation in laser doses. The highest response was observed with an exposure time of $40 \mathrm{~min}$. This result was reproduced in RBCs suspended in a buffered $\mathrm{NaCl}$ solution. In contrast to this finding, laser-induced $\mathrm{RBC}$ volume change was completely abolished by suspending RBCs in a solution containing a higher concentration of EDTA. Conclusions: It was suggested that LLL can reduce RBC volume possibly because of the increased free intracellular $\mathrm{Ca}^{+2}$ concentrations, which activate $\mathrm{Ca}^{+2}$-dependent $\mathrm{K}^{+}$channels with consequent $\mathrm{K}^{+}$ion efflux and cell shrinkage.
\end{abstract}

\section{Introduction}

D IODE PUMP SOLID STATE (DPSS) LASERS ARE widely used for low-level laser light therapy (LLLT). DPSS laser light is monochromatic, confining all the beam energy into a narrow wavelength band, which can be important for biomedical, holographic, spectroscopic, and other applications. The advantages of DPSS laser are its compactness, efficiency, and cost effectiveness in comparison with other types of lasers. ${ }^{1-3}$

Over the last few decades, many studies have been performed to investigate effects of LLL irradiation in medical science. ${ }^{4,5}$ However, the mechanisms of its effect on human blood components still have not been discovered sufficiently, and it is still a topic for discussion. The response of human blood to LLL irradiation gives important information about the interaction mechanism of laser irradiation with a living organism. ${ }^{4,6}$ However, some studies have examined the effects of LLL irradiation on human blood, especially on the red blood cells (RBCs). ${ }^{6-10}$ This study has been conducted to further understand the response of RBCs to LLL irradiation. However, the information regarding the response of human blood parameters is still lacking, such as $\mathrm{RBC}$ volume to low laser light irradiation.

Blood properties, of patients with different pathologies, are modified with LLL irradiation. ${ }^{11}$ Laser irradiation improves microcirculation, and modulates rheological properties of blood pathology. ${ }^{12}$ Laser irradiation induces conformational transitions of the red blood cell membrane, which is related to changes in the structural states of both erythrocyte membrane proteins and lipid bilayer, resulting in changes in the activity of membrane ion pumps. ${ }^{13}$ The laser-induced changes in various biological objects, such as blood components, have been the focus of previous studies. ${ }^{14}$ It is well known that the cell membrane is the first line of interaction between cellular machinery and the outer

\footnotetext{
${ }^{1}$ School of Physics, Department of Medical Physics, Universiti Sains Malaysia, Pulau Pinang, Malaysia.

${ }^{2}$ Department of Physiology, College of Medicine, Al-Mustansiriya, Iraq.

${ }^{3}$ Advanced Medical and Dental Institute, Universiti Sains Malaysia, Bertam Kepala Batas, Pulua Pinang, Malaysia.

(C) Mustafa S. Al Musawi, et al., 2016; Published by Mary Ann Liebert, Inc. This Open Access article is distributed under the terms of the Creative Commons License (http://creativecommons.org/licenses/by/4.0), which permits unrestricted use, distribution, and reproduction in any medium, provided the original work is properly credited.
} 
environment. It is the site of key events in laser interaction with cells. ${ }^{5}$ The red blood cell membrane is most prominent because of its simplicity, availability, and physiological importance. ${ }^{15}$ A number of studies have been conducted, both in vitro and in vivo, that shows the significant influence of laser irradiation on the red blood cell functions. Moreover, a group of researchers found undetectable effects of laser exposure. ${ }^{13}$

This study aimed to investigate the in vitro effects of different low-level DPSS laser doses of the wavelength $405 \mathrm{~nm}$ on mean cell volume (MCV) in human blood.

\section{Materials and Methods}

\section{Blood samples}

Fresh human blood samples were collected at the $\mathrm{He}-$ matology Laboratory, Advanced Medical and Dental Institute (AMDI), Universiti Sains Malaysia (USM), Pinang, Malaysia. Apparently healthy adults were selected and convinced to participate in this study after being briefed about the aims and objectives of the study and assured about the privacy of the confidential data. The blood samples collection was approved by USM Research Ethics Committee (Human). The blood samples, of $5 \mathrm{~mL}$, were collected from all the participants through a venipuncture into ethylenediaminetetraacetic acid (EDTA)-containing tubes $(1.3 \mathrm{mg} / \mathrm{mL}$ of blood) as anticoagulant. The samples were then processed immediately after collection. Each sample was divided into two equal parts to be used as an unirradiated control sample and an irradiated sample. The samples were analyzed within 2 days after collection.

\section{Laser irradiation}

The blood samples were irradiated with a low-power laser beam of $405 \mathrm{~nm}$ from a DPSS (model F Series, Changchun Dragon Lasers Co.) (Transverse mode, $\mathrm{TEM}_{00}$ ), with an output power of $10 \mathrm{~mW}$. Optical power was calibrated using a Newport multifunction optical meter (model 2936-C). The blood samples, contained in $2.5 \mathrm{~mL}$ tubes, were irradiated with a laser beam of $0.332 \mathrm{~cm}^{2}$, with a power density of $0.03 \mathrm{~W} / \mathrm{cm}^{2}$, for $20,30,40$, and $50 \mathrm{~min}$. The delivered dose, for each irradiated group, was $36,54,72$, and $90 \mathrm{~J} / \mathrm{cm}^{2}$, respectively. The laser beam was directed normally to the blood-sample-containing tubes, from up to down (only one point, in the center of the test tube). The irradiation was performed at room temperature $\left(23 \pm 2^{\circ} \mathrm{C}\right)$.

\section{MCV measurement}

The MCV was measured before and after irradiation for each blood sample using a computerized hematology analyzer (Mindray BC-3200). All the measurements were performed immediately after irradiation for the irradiated samples. Data for the MCV and RBC count are an average of four repeated measurements.

\section{Processing and irradiation of $R B C$ suspension}

Separation of blood components was achieved by centrifugation of blood, using bench centrifuge (MP $6000 \mathrm{R}$, Eltek. Co. India) at $3000 \mathrm{rpm}$ for $5 \mathrm{~min}$. The plasma, buffy coat, and uppermost layers of packed RBCs were discarded.
The packed RBCs were washed thrice in $0.9 \% \mathrm{NaCl}$ solution through resuspension and recentrifugation of the $\mathrm{RBC}$ suspension. Three aliquots of $250 \mu \mathrm{L}$ of washed packed RBCs were dispensed into three tubes. One of the tubes served as a control in which the red blood cells were resuspended in a $250 \mu \mathrm{L}$ solution containing in $m \mathrm{M}: \mathrm{NaCl}$ 150, Tris base 10, and $\mathrm{pH}$ 7.4. The washed RBCs were resuspended in a second tube, in the same solution as was contained in tube one. The contents of this tube were exposed to $72 \mathrm{~J} / \mathrm{cm}^{2}$ of DPSS laser light for $40 \mathrm{~min}$. In the third tube, the washed RBCs were resuspended in a $250 \mu \mathrm{L}$ solution containing in $m \mathrm{M}: \mathrm{NaCl} 150$, Tris base 10, EDTA 10, and $\mathrm{pH}$ 7.4. The contents of this tube were also exposed to laser radiation exactly as in the second tube. The preirradiation MCV and post-irradiation MCV of the RBCs of the suspended samples in each blood sample were measured using a computerized hematology analyzer.

\section{Statistical analysis}

Statistical analysis and calculation were performed using SPSS software. The difference between the controlled and irradiated samples was evaluated by applying a paired sample student $t$ test. The $p$ value was determined according to analysis of the significance of difference. A $p$ value of $<0.05$ was considered significant. All results are expressed as mean $\pm \mathrm{SD}$.

\section{Results}

\section{Effects of $405 \mathrm{~nm}$ laser irradiation on $R B C$ volume}

The blood samples were irradiated, in vitro, using a $405 \mathrm{~nm}$ DPSS laser light with $10 \mathrm{~mW}$ irradiation power. No hemolysis or morphological changes of the erythrocytes were observed. No significant differences in RBC count were observed between pre-irradiated and post-irradiated samples, as shown in Table 1.

The MCV change is observed as a function of irradiation dose as summarized in Fig. 1. Various doses were applied and found able to induce significant changes in RBC volume ( $p<0.05, p<0.0001, p<0.0001$, and $p<0.05$, respectively). It is clear that in vitro irradiation of human blood to DPSS $405 \mathrm{~nm}$ laser significantly decreases the MCV at doses of 36, 54,72 , and $90 \mathrm{~J} / \mathrm{cm}^{2}$. The dose of $72 \mathrm{~J} / \mathrm{cm}^{2}$ is optimum; it results in maximum MCV decrease, $0.44 \%$, of healthy human RBCs, in comparison with unirradiated RBCs.

\section{Effects of $405 \mathrm{~nm}$ laser irradiation on RBCs suspended in artificial suspending media}

The MCV of RBCs suspended in EDTA-free solution, irradiated to $72 \mathrm{~J} / \mathrm{cm}^{2}$ from a $405 \mathrm{~nm}$ laser, is significantly smaller (by $0.2 \%$ ) than that of unirradiated RBCs suspended in same solution, as shown in Fig. 2. This clearly indicates that irradiation causes a significant decrease in RBC volume. In contrast to this finding, laser-induced RBC volume change was found to be completely abolished by suspending RBCs in EDTA-containing solution.

\section{Discussion}

This study was aimed to determine the effectiveness of the $405 \mathrm{~nm}$ DPSS laser as a LLL on the RBC volume in 
Table 1. RBC Count and MCV Before and After LLL Irradiation

\begin{tabular}{lccccc}
\hline Dose $\left(\mathrm{J} / \mathrm{cm}^{2}\right)$ & Blood parameters & Unirradiated mean $\pm S D$ & Irradiated mean $\pm S D$ & Difference mean $\pm S D$ & $\mathrm{p}$ Value \\
\hline 36 & $\mathrm{RBC}\left(\times 10^{12}\right) / \mathrm{L}$ & $4.90 \pm 0.36$ & $4.90 \pm 0.36$ & $0.0005 \pm 0.007$ & 0.683 \\
& $\mathrm{MCV}(\mathrm{fL})$ & $89.11 \pm 2.58$ & $88.92 \pm 2.57$ & $0.185 \pm 0.49$ & 0.049 \\
54 & $\mathrm{RBC}\left(\times 10^{12}\right) / \mathrm{L}$ & $4.66 \pm 0.54$ & $4.66 \pm 0.55$ & $0.001 \pm 0.01$ & 0.527 \\
& $\mathrm{MCV}(\mathrm{fL})$ & $88.75 \pm 2.04$ & $88.39 \pm 2.13$ & $0.352 \pm 0.45$ & 0.0001 \\
72 & $\mathrm{RBC}\left(\times 10^{12}\right) / \mathrm{L}$ & $5.18 \pm 0.48$ & $5.17 \pm 0.48$ & $0.004 \pm 0.02$ & 0.386 \\
& $\mathrm{MCV}(\mathrm{fL})$ & $89.82 \pm 2.99$ & $89.42 \pm 3.07$ & $0.396 \pm 0.235$ & 0.0001 \\
90 & $\mathrm{RBC}\left(\times 10^{12}\right) / \mathrm{L}$ & $5.23 \pm 0.50$ & $5.23 \pm 0.50$ & $0.0002 \pm 0.003$ & 0.697 \\
& $\mathrm{MCV}(\mathrm{fL})$ & $89.09 \pm 2.49$ & $89.04 \pm 2.51$ & $0.049 \pm 0.120$ & 0.033 \\
\hline
\end{tabular}

$\mathrm{RBC}$, red blood cell; MCV, mean cell volume; LLL, low-level laser.

human blood. The laser radiation in the violet spectral region has been used in this study because hemoglobin absorbs maximum light in this region as compared with other spectral regions, this result in light penetration deep into living tissue. ${ }^{16}$ The LLL is a special type of laser that affects biological systems through nonthermal means. In this system, temperature elevation in the irradiated tissue is limited to $<0.1-0.5^{\circ} \mathrm{C}{ }^{16,17}$ In this study, the RBCs were exposed to different LLL doses and significant decrease in the MCV is observed. Similar results are reported previously where LLL was used with different wavelengths. ${ }^{18,19}$ Four different doses were selected to perform intercomparisons between the doses. The comparison was made with an unirradiated control group. The maximum decrease in MCV was observed with a dose of $72 \mathrm{~J} / \mathrm{cm}^{2}$. This LLL dose produces optimum results as compared with any other dose. This illustrates the basic concept of the biphasic dose response or hormesis. ${ }^{20}$ Sufficient energy is needed to overcome the threshold to obtain a response; however, energy greater than threshold energy is required to replace biostimulation with bioinhibition. ${ }^{21,22}$

The MCV of RBCs suspended in EDTA-free solution and irradiated with dose of $72 \mathrm{~J} / \mathrm{cm}^{2}$ at $405 \mathrm{~nm}$ is shown in Fig. 2. A reduction in RBC volume could be explained on the basis of ion fluxes. It is possible that the reduction of $\mathrm{RBC}$ volume upon irradiation (while the cells are suspended

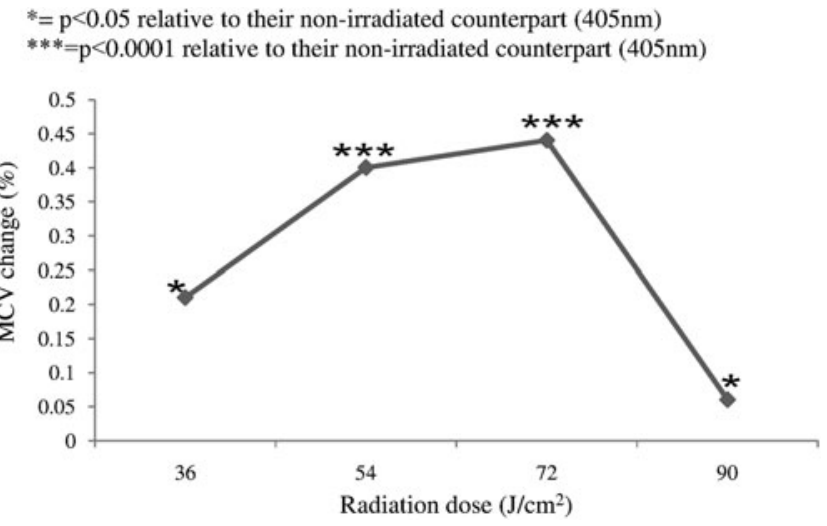

FIG. 1. Percent change in mean cell volume (MCV) with change in radiation dose $(n=30$ for each specific dose). ${ }^{*} p<0.05$ relative to their unirradiated counterpart $(405 \mathrm{~nm}) . * p<0.0001$ relative to their unirradiated counterpart $(405 \mathrm{~nm})$. in EDTA-free solution) is caused by the activation of $\mathrm{Ca}^{+2}-$ dependent $\mathrm{K}^{+}$channels. Under normal conditions, it is possible to expect that free $\mathrm{Ca}^{+2}$ is present at a very low concentration (micromolar or submicromolar level) in the solution used throughout this study. This is because of the use of distilled water rather than deionized water for preparation of solutions. Low-intensity laser induced conformational transitions of the RBC membrane, which are related to the changes in the activity of the membrane ion pumps and, as a result, changes in membrane ion flows. ${ }^{13}$

It is possible to suggest that laser light has the ability to disrupt the cell membrane layers. This disruption may lead to open pores for $\mathrm{Ca}^{+2}$ ions. The free $\mathrm{Ca}^{+2}$ then passes from the extracellular solution (EDTA-free solution) to the intracellular RBC fluid through cell membrane pores induced by laser light. The increased free intracellular $\mathrm{Ca}^{+2}$ concentrations stimulate the activation of $\mathrm{Ca}^{+2}$-dependent $\mathrm{K}^{+}$ channels. Upon stimulation of such channels, $\mathrm{K}^{+}$passes from inside of the cells, where the concentration of $\mathrm{K}^{+}$is high, to the extracellular fluid, where there are no $\mathrm{K}+$ ions $\left(\mathrm{K}^{+}\right.$efflux according to concentration gradient). This $\mathrm{K}^{+}$ movement is also associated with water molecules movement (law of osmosis). Accordingly, smaller RBCs were yielded. Adding EDTA to the suspending solution was

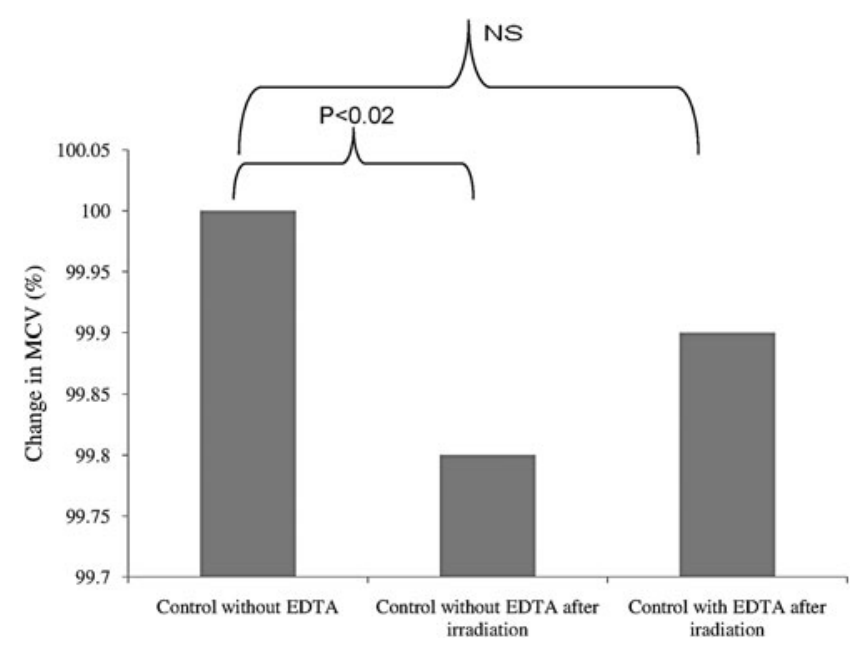

FIG. 2. Post-irradiation mean cell volume (MCV) of red blood cells (RBCs) in the absence and presence of ethylenediaminetetraacetic acid (EDTA) (number of samples =14). 
shown to completely obliterate the effect of $\mathrm{Ca}^{+2}$ in inducing such volume changes upon irradiation by chelating all available free extracellular $\mathrm{Ca}^{+2}$. The results may also explain the reduction of $\mathrm{RBC}$ volume upon laser irradiation in whole blood samples collected in EDTA-containing tubes. This is because the amount of EDTA in such tubes is enough to chelate $\mathrm{Ca}^{+2}$ and prevent blood coagulation cascade, but still not high enough to chelate all available free $\mathrm{Ca}^{+2}$ ions.

\section{Conclusions}

The maximum decrease in $\mathrm{MCV}$ is observed with the irradiation dose of $72 \mathrm{~J} / \mathrm{cm}^{2}$. Accordingly, it is possible to conclude that this is the optimum dose that produces optimized results. The exposure of RBCs to LLL can reduce $\mathrm{RBC}$ volume possibly because of the increased free intracellular $\mathrm{Ca}^{+2}$ concentrations, which activate $\mathrm{Ca}^{+2}$-dependent $\mathrm{K}^{+}$channels.

\section{Author Disclosure Statement}

No competing financial interests exist.

\section{References}

1. Davarcioglu B. An overview of diode pumped solid state (DPSS) lasers. Int Acad Arts Sci Technol 2010;1:1-12.

2. Ion J. Laser processing of engineering materials: principles, procedure and industrial application. Burlington: ButterworthHeinemann, 2005.

3. Yao JY, Wang Y. Nonlinear optics and solid-state lasers: advanced concepts, tuning-fundamentals and applications. New York: Springer Science \& Business Media, 2012.

4. Prokopova L, Losev A, Ursol I. Effect of intravascular laser therapy on the rheologic properties of blood in children with bilateral destructive pneumonia. Klin Khir 1992;6:7-9.

5. Yova D, Haritou M, Koutsouris D. Antagonostic effects of epinephrine and helium-neon (He-Ne) laser irradiation on red blood cells deformability. Clin Hemorheol 1994;14; 369-378.

6. Zalesskaya G, Sambor E. Interaction of low-intensity laser radiation with blood and its components. J Appl Spectrosc 2005;72;242-248.

7. Houssien HA, Jafaar MS, Al Tamimi Z, Mustafa F, Ismail A, Ali Z. Influence of low power He-Ne Laser irradiation on hemoglobin concentration, mean cellular volume of red blood cell, and mean cellular hemoglobin. J Sain Kesiha Malays 2011;9:9-13.

8. Siposan DG, Lukacs A. Effect of low-level laser radiation on some rheological factors in human blood: an in vitro study. J Clin Laser Med Surg 2000;18;185-195.

9. Mi X, Chen JY, Cen Y, Liang ZJ, Zhou LW. A comparative study of 632.8 and $532 \mathrm{~nm}$ laser irradiation on some rheo- logical factors in human blood in vitro. J Photochem Photobiol B 2004;74:7-12.

10. Zalesskaya G, Sambor E, Kuchinskii A. Effect of intravenous laser irradiation on the molecular structure of blood and blood components. J Appl Spectrosc 2006;73;115-122.

11. Korolevich A, Oleinik T, Khairullina AY. Optical methods of studying the effect of laser radiation on human erythrocytes. J Appl Spectrosc 1992;57;651-654.

12. Ghadage V, Kulkarni G. Effects of Nd:YAG laser irradiation on human erythrocytes in vitro. Int J Integr Biol 2010; 9;149-151.

13. Kujawa J, Zavodnik L, Zavodnik I, Buko V, Lapshyna A, Bryszewska M. Effect of low-intensity $\left(3.75-25 \mathrm{~J} / \mathrm{cm}^{2}\right)$ near-infrared $(810 \mathrm{~nm})$ laser radiation on red blood cell ATPase activities and membrane structure. J Clin Laser Med Surg 2004;22;111-117.

14. Conlan MJ, Rapley JW, Cobb CM. Biostimulation of wound healing by low-energy laser irradiation. A review. J Clin Periodontol 1996;23;492-496.

15. Kaššák P, Sikurová L, Kvasnicka P, Bryszewska M. The response of $\mathrm{Na} / \mathrm{K}$-Atpase of human erythrocytes to green laser light treatment. Physiol Res 2006;55:189-194.

16. Vladimirov YA, Osipov A, Klebanov G. Photobiological principles of therapeutic applications of laser radiation biochemistry. Biochemistry 2004;69:103-113.

17. Karu TI. Low-power laser therapy. Biomed Photon Handbook 2003;48:1-25.

18. Siposan DG, Bobe S. Effects of HeNe laser on stored blood. Laser Ther 2010;19:245-255.

19. Mustafa YM, Amin SN, Abdalwahab S, Elsharbini AAM. Effects of non-coherent and coherent light on complete blood picture and osmotic fragility of human blood. J Blood Disorders Transf 2013;4:34.

20. Calabrese EJ. The future of hormesis: where do we go from here? Crit Rev Toxicol 2001;31:637-648.

21. Sommer AP, Pinheiro AL, Mester AR, Franke RP, Whelan HT. Biostimulatory windows in low-intensity laser activation: lasers, scanners, and NASA's light-emitting diode array system. J Clin Laser Med Surg 2001;19:29-33.

22. Huang Y-Y, Sharma SK, Carroll J, Hamblin MR. Biphasic dose response in low level light therapy. An Update. Dose Response 2011;9:602-618.

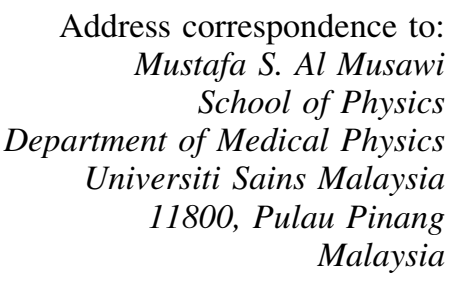

E-mail: laser_mu@yahoo.com 